\title{
Understanding the Impact of Personality Traits on Mobile App Adoption - Insights from a Large-Scale Field Study
}

\author{
Runhua $\mathrm{Xu}^{\mathrm{a}^{*}}$, Remo Manuel Frey ${ }^{\mathrm{a}}$, Elgar Fleisch ${ }^{\mathrm{a}, \mathrm{b}}$, Alexander Ilic ${ }^{\mathrm{b}}$ \\ ${ }^{a}$ Department of Management, Technology and Economics, ETH Zurich, Weinbergstrasse 56/58, 8092 Zurich, Switzerland \\ ${ }^{b}$ Institute of Technology Management, University of St.Gallen, Dufourstrasse 40a, 9000 St.Gallen, Switzerland
}

\begin{abstract}
The sheer amount of available apps allows users to customize smartphones to match their personality and interests. As one of the first large-scale studies, the impact of personality traits on mobile app adoption was examined through an empirical study involving 2043 Android users. A mobile app was developed to assess each smartphone user's personality traits based on a state-of-the-art Big Five questionnaire and to collect information about her installed apps. The contributions of this work are two-fold. First, it confirms that personality traits have significant impact on the adoption of different types of mobile apps. Second, a machine-learning model is developed to automatically determine a user's personality based on her installed apps. The predictive model is implemented in a prototype app and shows a $65 \%$ higher precision than a random guess. Additionally, the model can be deployed in a non-intrusive, low privacy-concern, and highly scalable manner as part of any mobile app.
\end{abstract}

Keywords: Mobile app adoption, adoption theory, personality traits, personality prediction, machine learning

Corresponding author. Tel.: +41-44-632-8256; Fax: +41-44-632-1740; E-mail address: rxu@ethz.ch 


\section{Introduction}

Smartphones are the most personal devices people own (Scornavacca \& Barnes, 2006) and carry around with them all day. The number of available mobile apps in major app stores now easily exceeds one million - providing an app for almost any situation of our life (Statista, 2014). Consequently, the kind of apps people install and use could be closely linked to their interest, demographics, and personality (Ryan \& Xenos, 2011; Seneviratne, Seneviratne, Mohapatra, \& Mahanti, 2014; Shen, Brdiczka, \& Liu, 2015). As shown in other research fields, personality traits can have a significant impact on an individual's decision-making process (Bettman, 1979; Sproles \& Kendall, 1986).

While research on the impact of personality on information system (IS) adoption is scarce, first works already demonstrated the relevance of personality for explaining people's adoption behavior (McElroy, Hendrickson, Townsend, \& DeMarie, 2007). Researchers in recent years find correlations between an individual's personality and her adoption of Internet usage (Landers \& Lounsbury, 2006; McElroy et al., 2007) and specific apps like 'Facebook' (Ryan \& Xenos, 2011) and 'Foursquare' (Chorley, Whitaker, \& Allen, 2015). The high adoption rate of mobile devices and apps makes mobile apps a highly relevant and interesting field to study from a broader perspective than just from a single app. As one of the first studies, this work aims to study the influence of personality traits on the adoption of different types of mobile apps from a large-scale field study. Consequently, practitioners like app publishers could leverage the knowledge to boost adoption of their mobile apps as well as to conduct more efficient market segmentation.

However, information about each smartphone user's personality traits remains unknown to app publishers until being measured. The effectiveness and scalability of current questionnaire-based approaches to measure personality traits are limited (Montjoye, Quoidbach, \& Robic, 2013). This work thus presents a scalable machine-learning approach to predict personality traits with information like app installations and update events (henceforth referred to as mobile app data) since they are suited as robust features (Pan, Aharony, \& Pentland, 2011). Unlike previous studies, data used in our predictive models are openly accessible to any app developer. This makes it possible to integrate the approach into any mobile app. In addition, there is no extra burden on the user to fill out a questionnaire. The predicted personality traits can also serve other decision support systems and recommendation systems to conduct more precise user profiling, better customer relationship management, as well as more effective personalized marketing.

The contributions of this work are two-fold: First, it provides insights into how the adoption of different types of mobile apps can be explained by the Big Five personality traits. The state-of-the-art questionnaire-based approach is used to determine personality traits. Previous research typically has a small number of samples and focuses on specific apps like 'Facebook' and 'Twitter'. Such limitation might influence the generalizability of the findings. Consequently, this work aims to classify a large number of apps into groups and analyze the impact of personality on each group to gain systematic knowledge.

Second, a scalable approach is generated to determine each smartphone user's Big Five personality traits based on her readily available mobile app data. A machine-learning algorithm is applied to solve the classification problem by using the Big Five-44 personality test as ground-truth for training, validation, and testing. The findings suggest that existing questionnaire-based approaches can be replaced by this highly scalable and efficient method. This enables a large-scale and cost-efficient exploration of mobile app adoption influenced by personality traits.

The rest of the paper is structured as follows. Section 2 presents related work on personality traits, user profiling, and IS adoption and Section 3 develops hypotheses. Section 4 introduces the research design in detail, which is followed by Section 5 that presents the empirical results. Finally, the paper concludes with a discussion of the limitations and an outlook on future work.

\section{Related Work}

\subsection{Personality Traits}

Five-factor models (FFM) (Mccrae \& Costa, 1987) of personality emerged as a broader taxonomy for personality-related issues and are embedded in a rich conceptual framework for integrating all research findings in 
personality psychology (Digman, 1990). The most widely used five factor model is called the Big Five personality traits, which consists extraversion (E), neuroticism $(\mathrm{N})$, agreeableness $(\mathrm{A})$, conscientiousness $(\mathrm{C})$, and openness to experience (O) (John \& Srivastava, 1999). Extraversion is frequently associated with being sociable, gregarious, talkative, and active (Eysenck, 1947); Neuroticism includes traits like being anxious, depressed, worried, nervous, and insecure (Eysenck, 1947); Common traits associated with the third dimension, namely agreeableness, refer to being courteous, trusting, cooperative, and tolerant (Norman, 1963); Conscientiousness represents traits such as being careful, thorough, responsible, organized, and planful (Norman, 1963); The last dimension, openness to experience, is typically associated with being imaginative, curious, broad-minded, and independent (Costa \& McCrae, 1985). Personality traits can have a significant impact on an individual's decision making (Bettman, 1979; Sproles \& Kendall, 1986). However, most research related to personality focus on job performance or career development (Penney, David, \& Witt, 2011).

An individual's personality traits like the Big Five are usually measured based on questionnaires (Murray, Barrick, \& Mount, 1991; Gosling, Rentfrow, \& Swann, 2003; John \& Srivastava, 1999; Judge, Heller, \& Mount, 2002). Instruments such as the Trait Descriptive Adjectives (Goldberg, 1992), 60-item NEO Five-Factor Inventory (Costa \& McCrae, 1985), NEO Personality Inventory, Revised (Costa \& McCrae, 1992; McCrae \& Costa, 2004), and the Big Five-44 Inventory (John \& Srivastava, 1999) were developed for accurate measurement. However, in spite of the ubiquity of the questionnaire-based approach in research and practice, its problem is obvious: Answering a questionnaire is time-consuming. To finish a questionnaire with one of the above-mentioned inventories typically requires five to fifteen minutes (Gosling et al., 2003). A vast amount of research therefore dealt with addressing non-participation through survey length reduction (Bergkvist \& Rossiter, 2007; Childers \& Ferrell, 1979; Gosling et al., 2003) or interpreting unanswered questions (Porter 2004; Bosnjak et al. 2005). Even though the Internet has facilitated addressing vast amounts of people simultaneously, participation rates for online surveys are roughly $30 \%$ (Nulty, 2008). Taking the time and cost occurred in distributing and collecting questionnaires into account, such an approach is only limitedly scalable.

\subsection{Automatic User Profiling}

Recent advances in information technology and machine-learning techniques have drawn the attention to datadriven and automatic approaches to overcome the limitations of the questionnaire-based approach. For instance, Kucukyilmaz et al. (2006) were able to predict a person's gender by mining her chatting records. Ying et al. (2007) predicted a user's gender from analyzing her online Web browsing behavior. In addition to gender, a person's age could also be predicted automatically. Nguyen et al. (2011) concluded that a person's age was predictable through analyzing her blog texts, telephone conversations, and online forum posts. Guo et al. (2008) and Han et al. (2014) detected a person's age and gender by leveraging face recognition technologies. Kosinski et al. (2013) were able to predict a 'Facebook' user's gender, race and marriage status from investigating her Facebook Likes. Recently, researchers tried to predict not only demographics but also other user characteristics like personality traits. Pianesi et al. (2008) extracted audio and video features from meetings and used them to predict each meeting participant's two personality traits, extraversion and locus of control. Wright and Chin (2014) predicted an author's Big Five personality traits based on the texts she had written. Similarly, researchers revealed a possibility to automatically predict a person's personality through analyzing her email content (Shen, Brdiczka, \& Liu, 2013) and social network content like 'Facebook' and 'Twitter' (Bachrach, Kosinski, Graepel, Kohli, \& Stillwell, 2012; Chin \& Wright, 2014; Minamikawa, Fujita, Hakura, \& Kurematsu, 2012). With the proliferation of smartphones, other researchers (Chittaranjan, Blom, \& Gatica-Perez, 2013; Montjoye et al., 2013; Pan et al., 2011; Trestian \& Nucci, 2009) started to use mobile meta-data such as logs of phone calls, SMSs, and location information to predict a mobile phone user's personality traits.

The data-driven approaches are cost-effective and scalable (Montjoye et al., 2013), and contribute to overcome the intention-behavior gap (Conner \& Armitage, 1998; Godin \& Kok, 1996; Sheeran, 2002). However, while the results of these approaches are promising, they have a few drawbacks. First, part of the data used in the studies (like phone call and SMS records) is only available to phone manufacturers or telecommunication service providers. Second, some approaches require the installation of additional data logging software on a mobile phone, while others have to parse the content of personal emails and social network activities like 'Facebook Likes' and number of friends. Those actions could trigger strong privacy concerns thereby limiting the feasibility of use in reality. 
Third, some approaches require a long history of events (typically half a year) to provide reasonable results. Last but not least, most of the above-mentioned studies, especially the ones that make predictions based on mobile phone data, leverage modern machine-learning algorithms to predict the personality traits. However, with small samples in those studies, the result is not reliable and could overestimate the prediction performance due to over-fitting (Hastie, Tibshirani, \& Friedman, 2009; James, Witten, Hastie, \& Tibshirani, 2014). Consequently, a large-scale study that leverages a non-intrusive and highly scalable approach to predict a user's personality traits is required to fill those research gaps.

\subsection{Personality and IS Adoption Research}

Adoption and diffusion research is regarded as one of the most mature research areas in the IS discipline. It focuses on a better understanding of various factors that lead to the adoption of some innovations or the rejection of others. The theories that are widely applied in adoption researches are the Theory of Reasoned Action (TRA) (Ajzen \& Fishbein, 1980), the Theory of Planned Behavior (TPB) (Ajzen, 1985), the Technology Acceptance Model (TAM) (Davis, 1989), the Decomposed Theory of Planned Behavior (DTPB) (Taylor \& Todd, 1995), the Unified Theory for the Acceptance and Use of Technology (UTAUT) (Venkatesh, Morris, \& Davis, 2003; Venkatesh, Thong, \& Xu, 2012), and the Innovation Diffusion Theory (IDT) (Rogers, 1995).

Venkatesh et al. (2012) provided a good overview on different theories for IS adoption and relevant cognitive determinants. Among all of them, previous research (Arts, Frambach, \& Bijmolt, 2011; Dwivedi, Williams, Ramdani, Niranjan, \& Weerakkody, 2011; Moore \& Benbasat, 1991; Venkatesh \& Susan, 2001) indicated that determinants like relative advantage (Rogers, 1995), ease of use (Davis, 1989), compatibility (Rogers, 1995), enjoyment (Choudrie, Pheeraphuttharangkoon, Zamani, \& Giaglis, 2014), network influence (Leonard-Barton \& Deschamps, 1988), perceived cost (Wejnert, 2002), and privacy concerns (Rogers, 1995; Zhu, Dong, Xu, \& Hally, 2006) usually have direct impact on an individual's adoption decision.

Most individual level IS adoption research focused on analyzing the impact of these constructs on different innovations. However, as revealed by Wejnert (2002), relatively few research had investigated the impact of personal characteristics on innovation adoption. But it seems that such characteristics could be relevant to an individual's adoption decision (Weimann \& Hans-Bernd, 1994). As one of the few early studies, Menzel (1960) showed that self-confidence and risk-taking characteristic of individual actors affected their acceptance to novel information and applications. Similarly, other researchers (Agarwal \& Prasad, 1998; Brancheau \& Wetherbe, 1990; Leonard-Barton \& Deschamps, 1988) argued that personal innovativeness and openness positively influenced an individual's adoption of new technologies. With the wide adoption of the Internet in the beginning of twenty-first century, researchers started to investigate the impact of personality on general Internet adoption. They found that all the Big Five personality traits are significantly correlated with people's use of Internet as well as some special online apps such as chat rooms, information sharing, and Web browsers (Amiel \& Sargent, 2004; Constantiou, Damsgaard, \& Knutsen, 2006; Landers \& Lounsbury, 2006; Swickert, Hittner, Harris, \& Herring, 2002; Tuten \& Bosnjak, 2001). McElroy et al. (2007) concluded that individual's personality traits explained more variances in her use of Internet and online selling behavior than her cognitive style. In addition to general Internet use, the authors called future research to focus on examining the impact of personality on more specific types of IS adoption and use.

\section{Hypotheses Development}

Because mobile apps are ubiquitous, mostly free, and designed for individual use (Liu, Au, \& Choi, 2014), what factors influence an individual's adoption of mobile apps could be different from previous knowledge about traditional IS adoption. Following the proliferation of smartphones and mobile apps, research is thus required to understand the impact of personality on mobile app adoption thereby answering the call for research of McElroy et al. (2007). Consequently, this study examines previous literature and then generates hypotheses about what personality traits might impact people's adoption of different types of mobile apps.

To our best knowledge, there is no scientific categorization of mobile apps. Therefore, current app categorization of the largest mobile app store, Google Play Store, is taken as a reference. There are 29 different types of mobile apps in the Google Play Store. Some are extremely popular among smartphone users such as social, music and gaming apps, while others have small number of users such as comics and medical apps. To prevent information 
overflow, this study focuses on seven categories of mobile apps that are popular among users and could be correlated to the Big Five personality traits, as indicated in previous research. The seven categories are: mobile social apps (e.g. social media apps, chatting \& messaging apps), mobile games, mobile music \& video apps, mobile shopping apps, mobile photography apps (e.g. editing and polishing photos, photo filters), mobile finance apps (e.g. mobile banking, budget planning, expense management), and mobile personalization apps (e.g. changing ringtones, wallpapers, fonts).

Extraversion. People who are high in extraversion are social, outgoing, active and talkative. They place a high value on close and warm interpersonal relationship (Watson \& Clark, 1997). Extraverts do not regard online socialization as a substitute for offline socialization; they tend to make friends offline and keep them in touch online (Ross et al. 2009). Correa et al. (2010) revealed that extraversion was positively related to the use of social network and instant messaging apps. The finding was also supported by researchers (Ryan \& Xenos, 2011) in examining the use of 'Facebook'. In addition, extraverted people are willing to share information with others (Amiel \& Sargent, 2004), which is one of the key functions of current social network apps. As a result, extraverted people are expected to be more likely to adopt mobile social apps.

H1a. Extraversion is positively associated with the adoption of mobile social apps.

On the other hand, introverts are more social-isolated and tend to avoid direct social contact. Thus, instead of meeting friends or participating in social activities, introverted people tend to stay alone and take individual activities. Chittaranjan et al. (2013) found out that extraversion has a negative correlation with playing computer games. This negative association was also reported by the work of Meng et al. (2014). Although other researchers found positive correlation between extraversion and game playing (Tan \& Yang, 2014), we still believe that:

H1b. Extraversion is negatively associated with the adoption of mobile gaming apps.

Neuroticism. People high in neuroticism are anxious, depressed, worried, nervous and sensitive, while those who are low in neuroticism are emotionally stable and do not react negatively to life situations. The distrust inherent in neurotic people makes them more likely to regard new technologies and services as threatening and stressful thereby reducing their use of Internet (Devaraj, Easley, \& Michael Crant, 2008; Tuten \& Bosnjak, 2001). In addition, neuroticism was also found to be negatively correlated with the perceived usefulness and behavioral control (Uffen, Kaemmerer, \& Breitner, 2013), which in return reduced people's intention to adopt new technologies. However, empirical studies revealed contradictory results. Amiel and Sargent (2004) argued that neurotic people do spend more time online particularly in relation to social uses to gain a sense of belonging. Similarly, they indeed spend more time on social media and instant messenger to avoid loneliness (Butt \& Phillips, 2008; Correa et al., 2010; Ryan \& Xenos, 2011). Furthermore, previous research found that emotionally unstable people sometimes use shopping to regulate their moods (Tuten \& Bosnjak, 2001). This leads to the following hypotheses:

H2a. Neuroticism is positively associated with the adoption of mobile social apps.

H2b. Neuroticism is positively associated with the adoption of mobile shopping apps.

Empirical studies found out that neuroticism is positively associated with a fussy and picky attitude (MacNicol, Murray, \& Austin, 2003). Therefore, it is not irrational to assume that people high in neuroticism tend to use apps that improve the quality of existing stuffs. For instance, instead of using default settings, they are more likely to customize wallpapers, fonts, and ring tones to make their smartphones more unique and beautiful. Similarly, they are also expected to use mobile apps to edit and polish photos that are taken directly from smartphones. On the other hand, neuroticism is positively correlated with an individual's level of creativity (Gelade, 1997; Post, 1994), which in return makes her more likely to be interested in creative activities such as crafts, photography, design, drawing, writing, etc. Consequently,

H2c. Neuroticism is positively associated with the adoption of mobile photography apps.

H2d. Neuroticism is positively associated with the adoption of mobile personalization apps.

Agreeableness. People with high agreeableness are courteous, trusting, tolerant, and are more willing to help others. The tolerant and forgiving nature make them easier to accept new technologies and spend more time online (Devaraj et al. 2008). Agreeable individual were also found to be more persistent in investigating frustrating Websites that are user-unfriendly and difficult to navigate (Landers \& Lounsbury, 2006).

However, disagreeable people are found to have more online social contacts because Internet provides a means to 
build friendships that may be difficult for disagreeable people to build in offline situations (Hughes et al. 2012). On the other hand, other people also prefer to use online social media or telephone to contact disagreeable people to avoid direct face-to-fact interaction (Butt \& Phillips, 2008). This leads to the following hypothesis:

H3a. Agreeableness is negatively associated with the adoption of mobile social apps.

Furthermore, disagreeable individuals use mobile phones as a means to represent or display themselves. Therefore, they care more about some superficial elements of their mobile phones (e.g. changing wallpapers and ring tones) in order to achieve self stimulatory purpose and/or to attract the attention of other people (Butt \& Phillips, 2008). Thus,

H3b. Agreeableness is negatively associated with the adoption of mobile personalization apps.

Conscientiousness. Conscientiousness represents traits such as being organized, self-control, careful, persistence, and reliable. As these traits are closely associated with intrinsic motivation, conscientious contributes to an individual's high performance in study and jobs (Barrick \& Mount, 2000). Conscientious people are self-disciplined and intrinsically motivated to success (Uffen et al., 2013), therefore, they are less likely to use leisure mobile apps because they regard them as distracting and unproductive. The key support of this argument was found in the work of Landers and Lounsbury (2006) and Chittaranjan et al. (2013), which argued that conscientiousness was significantly and negatively correlated with the use of music and video apps. Similarly, it is also expected that less conscientious people are more likely to adopt other leisure apps such as photography apps and personalization apps. Due to the fact that conscientiousness is negatively correlated with creativity (King, Walker, \& Broyles, 1996), it is not surprising that less conscientious people tend to use mobile apps to design, edit and polish photos, wallpapers, and the like. Therefore,

H4a. Conscientiousness is negatively associated with the adoption of mobile music \& video apps.

H4b. Conscientiousness is negatively associated with the adoption of mobile photography apps.

H4c. Conscientiousness is negatively associated with the adoption of mobile personalization apps.

In addition, Ryan and Xenos (2011) and Hughes et al. (2012) found that conscientiousness is negatively correlated with the adoption of social network apps like 'Facebook' and 'Twitter' because conscientious individuals are cautious online and may choose to have social contacts offline. Also, people with high conscientiousness are more planful and organized. It is thus expected that more conscientious people are more likely to install finance apps that are typically expense manager, budget planner, and mobile banking. This leads to the following hypotheses:

H4d. Conscientiousness is negatively associated with the adoption of mobile social apps.

H4e. Conscientiousness is positively associated with the adoption of mobile finance apps.

Openness to Experience. Openness to experience people are imaginative, broad-minded, independent, and willing to try new things and seek for different experiences. Therefore, they are likely to become innovators and early adopters of new technologies and services (Constantiou et al., 2006; Tuten \& Bosnjak, 2001). Take social media and short messaging apps for example: Open to experience individuals have already started to use these apps in the beginning of online social networking era when the majority of population have not heard about them. As a result, early research confirmed that openness was positively correlated with the use of social apps (Butt \& Phillips 2008; Correa et al. 2010). However, as the innovation diffused quickly over time, early majority and late majority started to use such social apps (Rogers, 1995). Because the majority people are not open to experience by nature, their adoption of social apps reduces the level of openness of adopters towards the average level of the whole population. Consequently, later research could not confirm the effect of openness on the adoption of social apps like 'Facebook' and 'Whatsapp' anymore (Chorley et al., 2015; Landers \& Lounsbury, 2006; Ross et al., 2009; Tan \& Yang, 2014). Researchers thus claimed that the impact of openness on adoption is much limited than thought, especially when apps become mainstreams with a large number of adopters. Due to the fact that the app categories under study in this work such as social, games, music, and shopping are all mainstream apps, it is expected that openness to experience will have no impact on the adoption of any app category.

H5. Openness to experience is not associated with the adoption of any of the seven types of mobile apps. 


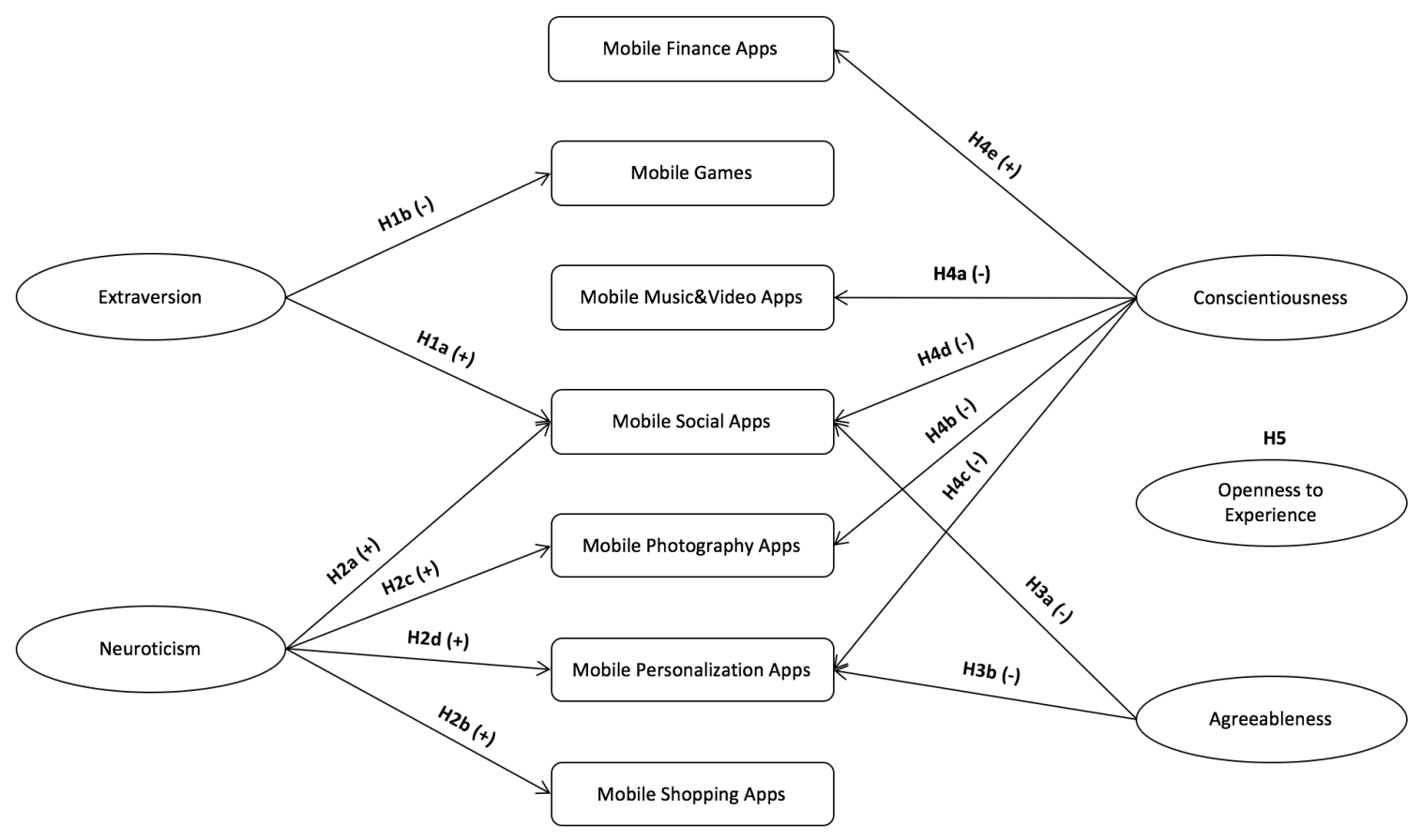

Fig. 1. Research Model

The research model is presented in Figure 1. A sign in the parentheses near each hypothesis indicates a positive or negative correlation between personality and the adoption of specific mobile apps.

\section{Research Design}

\subsection{Data Collection and Analysis for Hypotheses Testing}

To test the hypotheses, two types of data need to be collected. First, the Big-Five personality traits of each smartphone user need to be measured accurately. The Big Five-44 questionnaire (John \& Srivastava, 1999) that contains 44 questions to determine each user's Big-Five personality traits is used because it balances well the tradeoff between the length of a questionnaire and the reliability of measured result. Users rate all the measurements on a 1 to 5 scale, where 1 stands for totally disagree while 5 stands for totally agree. The ratings are calculated according to John and Srivastava (1999) and serve as ground-truth to represent users' scores on each of the Big Five dimensions.

Second, information about how each smartphone user adopts different types of mobile apps needs to be collected. Previous research typically use questionnaire to sample each participant's adoption behavior. In addition to the known disadvantages of the self-reported approach, it is not appropriate in the mobile app adoption context because users typically install a large number of apps and it is difficult for them to name all the apps they install and use in daily life. Instead of using questionnaire, actual app adoption records can be collected directly from the smartphone of each user, similar to the approach of Seneviratne et al. (2014). The Android operation system provides an Application Program Interface (API) for developers to retrieve mobile app data from each Android device (Seneviratne et al., 2014). The data comprises a full set of a user's installed mobile apps with four pieces of information: each app's package name, the time of the app's first installation, a timestamp that indicates when the app was latest updated, and a string value that represents the category the app belongs to on Google Play Store.

We developed an Android app called 'Personality Test!' to collect the two types of data at once. In addition, demographics like age, gender, salary, and educational level are also collected in the questionnaire to understand background of participants. The app is described as a personality test game that presents the user after successful 
completion with a nice personality feedback graph. Users give answers to the Big Five-44 measurement (as shown in Figure 2.a) and demographics (as shown in Figure 2.b) to compare her personality traits with the average of other people who have already participated in the game (as shown in Figure 2.c). The app presents a questionnaire as described above on the one hand and retrieves an Android device's mobile app data through the API on the other hand. Figure 2 shows the three main screens of the app.

When the app is opened for the first time, a random and unique string is generated to represent each participant. Meanwhile, a background process in the app is initiated, which reads the mobile app data from the device and sends it to the backend Web server. Once all the questions that measure personality or demographics are answered, the answers will be transmitted immediately to the backend server. In addition, after going to the next page, it is not possible to go back to the previous page to change answers. It is also impossible to redo the personality test on the same device more than once. These restrictions aim to prevent users from providing their own devices to others who also want to do the test. The app is listed on Google Play Store and it is distributed to Android phone users through Facebook pages, news feeds and posts. Users will not receive any monetary incentive for participating the study. The only motivation for them to install and use the app is to know their own personality traits and compare them with the average of others.

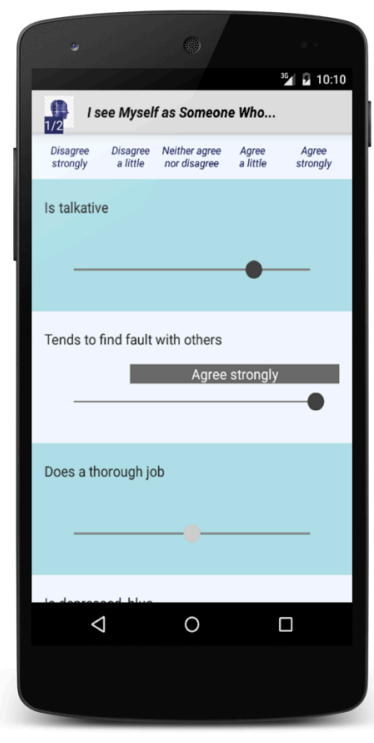

a) Big Five Question Battery

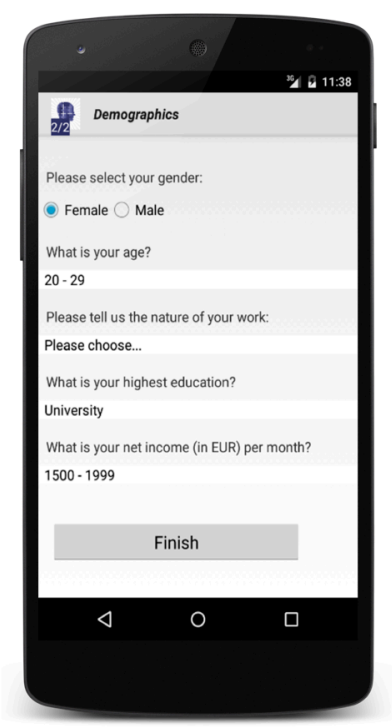

b) Demographic Questions

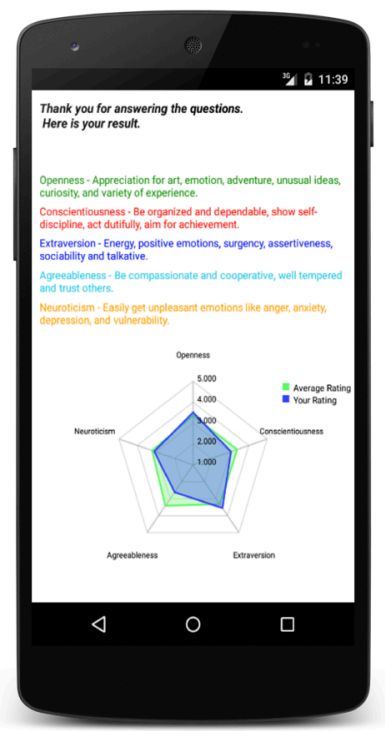

c) Results from Star Chart

Fig. 2. Screenshots of the Survey App

After collecting data, participants who fail to answer all the questions that measure the Big Five personality traits are excluded in the analysis to avoid inaccurate ratings. The remaining data points can be used to analyze the impact of personality on mobile app adoption. If a user has installed more than one app in one category, she will be regarded as an adopter of that category. The categorization is the same as that in the official Google Play Store.

In data analysis, a MANOVA is first performed on the means to help protect against inflating the Type 1 error rate in the follow-up ANOVAs and post-hoc comparisons, according to Cramer and Bock (1966). Prior to conducting the MANOVA, a series of Pearson correlation tests need to be performed between all of the dependent variables to test the MANOVA assumption that the dependent variables are not highly correlated with each other. In the MANOVA test, whether individuals are adopters of a specific category of apps serves as independent variable while their Big Five personality traits serve as dependent variables. If the covariance matrices between adopters and non-adopters are tested to be equal, MANOVA can then be applied. A statistically significant MANOVA result suggests that app adopters and non-adopters are different on at least one of the Big Five personality traits. 
Afterwards, Levene's F tests are conducted to check whether the homogeneity of variance assumption is satisfied. If the test results are non-significant, a series of follow-up ANOVAs and post-hoc comparisons can be applied to test what personality traits make the difference between adopters and non-adopters.

\subsection{Input Features and Indicators for the Machine-Learning Approach}

In addition to testing the hypotheses, another part of this study is to use the collected mobile app data to predict each smartphone user's Big Five personality traits. To generate reliable prediction models, three steps need to be further conducted. First, a lot of apps are pre-installed on Android devices by smartphone manufacturers. As such apps are not related to a user's behavior, they should be removed in the analysis. Second, users who install few apps or use her smartphone only recently should also be excluded because the short time of use might not mirror her personality traits. Third, each participant should be labeled as high, medium, or low on each of the Big Five personality traits to generate prediction models for classification. As indicated by Codish and Ravid (2014), there is no widely accepted guidance about what values account for a high or low personality trait. Previous research divides samples into two sets (high and low) based on the median value. However, Maccallum et al. (2002) argues that dichotomizing quantitative variables leads to loss of information about individual differences, loss of effect size and power, overlooking nonlinear effects, etc., and there have been no findings of positive consequence of dichotomization. Consequently, each participant is classified into one of the high, medium, or low groups on each of the Big Five personality dimensions according to Maccallum et al. (2002) and Shen et al. (2013).

Based on the literature of current data-driven approaches of predicting personality traits, novel indicators that can be easily and directly computed from the four pieces of mobile app data introduced in Section 4.1 are generated. The indicators that would meaningfully represent potential difference in personality traits are described below. The focus of this study is not to understand the causality between these indicators and individuals' personality traits. Instead, it aims to use readily accessible mobile app data to predict personality traits automatically and accurately.

Five genres of indicators can be calculated from the four pieces of mobile app data. The first genre is related to the number of app installations. Indicators are the total number of apps installs, the average number of app installs per month, the maximum, third-quartile (Q3), median, first-quartile (Q1), and minimum number of app installs per month, and the entropy of app installs per month. Entropy is a quantitative measure that reflects how evenly numbers in a group are distributed and it can be calculated according to Shannon and Weaver (1963). The second genre is related to the number of app updates. Indicators of this genre are similar to those of the first genre. The third genre is related to the app install intervals. An install interval is defined as the number of days between two sequential app installation days. Indicators of this genre are the average install intervals, the standard deviation of install intervals, as well as the maximum, third-quartile, median, first-quartile, and minimum number of app install intervals. In addition, the number of distinct app install days and the number of days since the first app was installed also belong to this genre. Similarly, its counterpart for app updates forms the fourth genre of indicators. The last genre is calculated based on the number of apps installed in each app category. The current app categorization on Google Play Store is taken as a standard because it is the largest app store on the market. Google Play Store distinguishes between 44 categories (27 general and 17 game categories) which are taken as indicators in this study. The information about in which category an app belongs to can be queried from the Google Play Store Webpage with app package name as a URL parameter. In total, 78 indicators that can be easily calculated based on mobile app data are generated and used for predicting a user's personality traits.

Based on the 78 basic indicators, an additional feature engineering is conducted to improve the accuracy of the machine-learning models. According to Guyon and Elisseeff (2003), interaction terms can be easily calculated and they are able to explain variance that cannot be explained by a single predictor. Therefore, interaction terms of influential app categories are used together with the basic indicators as independent variables to train the machinelearning models. Because the relationship between behavioral factors and personality traits are often non-linear (Benson \& John, 2007; Cucina \& Vasilopoulos, 2005), the Random Forest algorithm (Ho, 1995) is used in the modeling due to its ability to capture both linear and non-linear relationships and it usually performs better than other models in terms of prediction accuracy. In addition, Random Forest provides insights on what factors are more important in model generation and it almost cannot overfit (Hastie et al., 2009), which makes models less sensitive to variance.

All data samples are divided randomly into two sets: $70 \%$ samples in a training set and $30 \%$ samples in a test set. 
Parameters of the predictive models like number of predictors to consider at each branch split in Random Forest is tuned through cross-validation (James et al., 2014) on the training samples. The best-performed model is then applied on the separate test data set to check the prediction precision and recall.

\subsection{Study Running Environment}

In terms of running environment, the 'Personality Test!' app uses a Google API called 'android.content.pm' to retrieve information about installed apps on each Android device. The API is available since Android API Level 1. The app is compiled by Android Studio with the Software Development Kit (SDK) version 21.1.2. To leverage Facebook posts and feeds to distribute the app, an additional Facebook API called 'facebook-android-sdk' with version 3.23.1 is integrated in the app. The API links the app with a Facebook page and detects each app install that comes from the Facebook page. The 'Personality Test!' app is compatible with any Android device that has an operation system version higher than 4.0.3.

IBM SPSS software with version 22 is used to perform all the statistical analysis such as MANOVA, Pearson correlation test, Levene's F tests, etc. Regarding the development of machine-learning models, RStudio with version 0.99.486 is used. The package 'randomForest' with version 4.6 is used to build all the Random Forest Models and to tune the parameters.

\section{Result Analysis}

\subsection{Study Participants}

The personality test app was first published on Google Play Store in Germany on March 27, 2015. The corresponding Facebook feeds and posts were distributed between March 27, 2015 and April 1, 2015 to get participants. During this period, the Facebook promotion page was shown to 107,504 people and 2092 of them installed the app. The conversion rate for installation is around 2\%. Among the 2092 people who installed the app, 2043 people finished the full personality survey and 2008 people completed in addition the demographics questions. The distributions of the participants' demographics are shown in Table 1.

Table 1. Characteristics of Participants in the Study $(\mathrm{N}=2043)$

\begin{tabular}{|c|c|c|c|c|c|}
\hline Respondents & Range & In Percentage & Respondents & Range & In Percentage \\
\hline \multirow[t]{2}{*}{ Gender } & Female & $77.1 \%$ & Net Monthly Salary $(€)$ & $>5000$ & $0.4 \%$ \\
\hline & Male & $22.9 \%$ & & $4000-4999$ & $0.4 \%$ \\
\hline \multirow[t]{6}{*}{ Age } & $10-19$ & $21.7 \%$ & & $3000-3999$ & $1.6 \%$ \\
\hline & $20-29$ & $50.9 \%$ & & $2000-2999$ & $5.2 \%$ \\
\hline & $30-39$ & $17.9 \%$ & & $1500-1999$ & $13.2 \%$ \\
\hline & $40-49$ & $7.8 \%$ & & $1000-1499$ & $23.4 \%$ \\
\hline & $50-59$ & $1.4 \%$ & & $500-999$ & $23.2 \%$ \\
\hline & No Answer & $0.3 \%$ & & $<500$ & $17.9 \%$ \\
\hline \multirow[t]{9}{*}{ Job Type } & Permanent Job & $42.7 \%$ & & No Answer & $14.7 \%$ \\
\hline & Temporary Job & $0.8 \%$ & Highest Education & University & $5.2 \%$ \\
\hline & Self-employed & $2.4 \%$ & & High School & $14.8 \%$ \\
\hline & Student & $22.4 \%$ & & Vocational Education & $29.1 \%$ \\
\hline & Seeking for Jobs & $6.6 \%$ & & Secondary School & $44.9 \%$ \\
\hline & Housewife/man & $10.0 \%$ & & Elementary School & $1.4 \%$ \\
\hline & Retired & $0.7 \%$ & & No Degree & $4.6 \%$ \\
\hline & No Job & $1.5 \%$ & & & \\
\hline & No Answer & $12.9 \%$ & & & \\
\hline
\end{tabular}


The 2043 participants had on average 76 (S.D.=26) apps on their smartphones. Figure 3 (left) shows the distribution of the number of apps installed per participant. After removing all the pre-installed apps, participants had on average 31 (S.D.=22) apps on their mobile devices. The distribution of apps that are not pre-installed per participant is shown in Figure 3 (right). In total, 155,187 installed apps were observed - out of which 63,688 were not pre-installed and thus eligible for follow-up analysis.
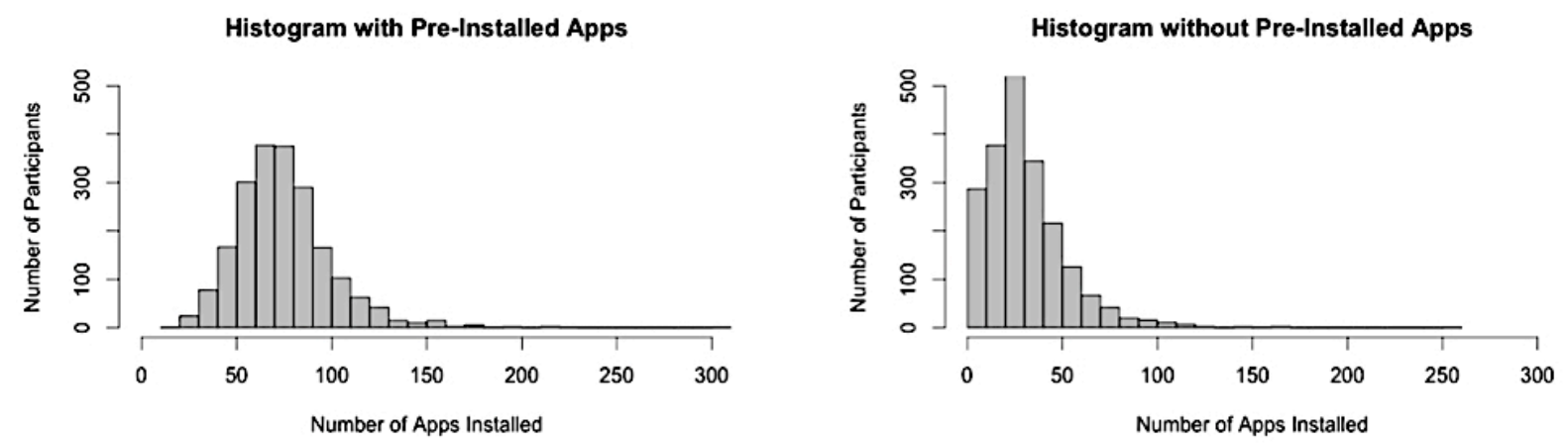

Fig. 3. Distribution of Apps Installed per Participant $(\mathrm{N}=2043)$

\subsection{Hypothesis Testing}

Before analyzing the data, the descriptive statistics and the reliability on each of the Big Five personality traits were examined. A Cronbach's Alpha metric was used to determine the reliability of the question batteries - whereas a Cronbach's Alpha of 0.90 is deemed excellent and a suggested value for a suggested value for a decent reliability is above 0.7 . As shown in Table 2, the reliability is very high with only agreeableness being slightly below the threshold. However, Nunnally (1967) claimed that a Cronbach's Alpha above 0.6 is already sufficient for early stages of research. In addition, Pearson correlation test was also performed to test the MANOVA assumption that the dependent variables are not strongly correlated. Results in Table 2 show that correlations between the Big Five dimensions are in the moderate range according to Meyers et al. (2013).

Table 2. Summary Statistics of the Big Five Personality Traits $(\mathrm{N}=2043)$

\begin{tabular}{|c|c|c|c|c|c|c|c|c|}
\hline & \multirow[t]{2}{*}{ Mean } & \multirow[t]{2}{*}{ S.D. } & \multirow{2}{*}{$\begin{array}{l}\text { Cronbach's } \\
\text { Alpha }\end{array}$} & \multicolumn{5}{|c|}{ Correlations } \\
\hline & & & & 1 & 2 & 3 & 4 & 5 \\
\hline Extraversion (E) & 3.335 & 0.748 & 0.810 & 1 & & & & \\
\hline Neuroticism $(\mathrm{N})$ & 3.209 & 0.738 & 0.752 & -.314 & 1 & & & \\
\hline Agreeableness (A) & 3.423 & 0.603 & 0.642 & .088 & -.237 & 1 & & \\
\hline Conscientiousness (C) & 3.382 & 0.639 & 0.749 & .287 & -.281 & .291 & 1 & \\
\hline Openness to Experience $(\mathrm{O})$ & 3.369 & 0.629 & 0.753 & .330 & -.162 & .121 & .250 & 1 \\
\hline
\end{tabular}

The results of hypotheses testing are shown in Table 3. To test H1a, the mean extraversion ratings of adopters and non-adopters of mobile social apps are compared. No statistically significant differences can be confirmed. Therefore, H1a is not supported. On the other hand, less extraverted people are found to be more likely to adopt mobile gaming apps $[F(1,2041)=6.74, p<.01]$, which supports $\mathrm{H} 1 \mathrm{~b}$.

Similarly, neuroticism is found to be positively associated with the adoption of mobile photography $[F(1,2041)=11.17, p<.001]$ and personalization apps $[F(1,2041)=12.10, p<.001]$. It is also found to be positively associated with the adoption of mobile social $[F(1,2041)=.32, n s]$ and shopping apps $[F(1,2041)=1.09$, ns], which is consistent with the hypotheses. However, the difference is not statistically significant. Consequently, H2c and $\mathrm{H} 2 \mathrm{~d}$ are supported while $\mathrm{H} 2 \mathrm{a}$ and $\mathrm{H} 2 \mathrm{~b}$ can not be supported.

To test $\mathrm{H} 3 \mathrm{a}$, the mean ratings of agreeableness between mobile social app adopters and non-adopters are 
compared. Although social app adopters are on average less agreeable than non-adopters, the difference is only significant at $90 \%$ confidence level $[F(1,2041)=2.69, p=.10]$. Therefore, H3a is not supported. On the other hand, agreeableness is found to be negatively associated with the adoption of mobile personalization apps $[F(1,2041)=4.21, p<.05]$ thereby supporting $\mathrm{H} 3 \mathrm{~b}$.

To test $\mathrm{H} 4 \mathrm{a}-\mathrm{H} 4 \mathrm{e}$, the mean ratings of conscientiousness of adopters and non-adopters are compared among five types of mobile apps. Conscientiousness is negatively associated with the adoption of mobile music \& video $[F(1,2041)=6.23, p<.05]$, photography $[F(1,2041)=7.11, p<.01]$, and personalization apps $[F(1,2041)=4.45$, $p<.05]$ thereby supporting $\mathrm{H} 4 \mathrm{a}, \mathrm{H} 4 \mathrm{~b}$ and $\mathrm{H} 4 \mathrm{c}$. In addition, adopters of mobile social apps are found to be less conscientious, however, the difference is only significant at $90 \%$ confidence level $[F(1,2041)=2.71, p=.10]$. For $\mathrm{H} 4 \mathrm{e}$, although adopters of mobile finance apps are found to be more conscientious than non-adopters $[F(1,2041)=3.88, p<.05]$, the Pillai's Trace of the previous MANOVA test is not significant $[F(5,2037)=1.065$, $p=.378]$. Therefore, H4e cannot be supported.

Table 3. Results of Hypotheses Testing

\begin{tabular}{|c|c|c|c|c|c|c|c|c|c|}
\hline \multirow[t]{2}{*}{ Hypothesis } & \multirow[t]{2}{*}{ Personality Traits } & \multirow[t]{2}{*}{ App Type } & \multicolumn{2}{|c|}{ Adopters } & \multicolumn{2}{|c|}{ Non-Adopters } & \multirow[t]{2}{*}{$\mathrm{F}$} & \multirow[t]{2}{*}{$\mathrm{P}$} & \multirow[t]{2}{*}{ Outcome } \\
\hline & & & $\mathrm{N}$ & M. (S.D.) & $\mathrm{N}$ & M. (S.D.) & & & \\
\hline H1a & Extraversion & Social & 1705 & $3.33(.75)$ & 338 & $3.36(.72)$ & .46 & ns & Not supported \\
\hline $\mathrm{H} 1 \mathrm{~b}$ & Extraversion & Gaming & 1630 & $3.32(.75)$ & 413 & $3.42(.71)$ & 6.74 & $<.01$ & Supported \\
\hline $\mathrm{H} 2 \mathrm{a}$ & Neuroticism & Social & 1705 & $3.21(.74)$ & 338 & $3.19(.74)$ & .32 & ns & Not supported \\
\hline $\mathrm{H} 2 \mathrm{~b}$ & Neuroticism & Shopping & 1429 & $3.22(.73)$ & 614 & $3.18(.76)$ & 1.09 & ns & Not supported \\
\hline $\mathrm{H} 2 \mathrm{c}$ & Neuroticism & Photography & 1076 & $3.26(.74)$ & 967 & $3.15(.73)$ & 11.17 & $<.001$ & Supported \\
\hline $\mathrm{H} 2 \mathrm{~d}$ & Neuroticism & Personalization & 573 & $3.30(.74)$ & 1470 & $3.17(.73)$ & 12.10 & $<.001$ & Supported \\
\hline $\mathrm{H} 3 \mathrm{a}$ & Agreeableness & Social & 1705 & $3.42(.59)$ & 338 & $3.48(.64)$ & 2.69 & ns & Not supported \\
\hline $\mathrm{H} 3 \mathrm{~b}$ & Agreeableness & Personalization & 573 & $3.38(.58)$ & 1470 & $3.44(.61)$ & 4.21 & $<.05$ & Supported \\
\hline $\mathrm{H} 4 \mathrm{a}$ & Conscientiousness & Music \& Video & 1582 & $3.36(.63)$ & 461 & $3.45(.65)$ & 6.23 & $<.05$ & Supported \\
\hline $\mathrm{H} 4 \mathrm{~b}$ & Conscientiousness & Photography & 1076 & $3.35(.65)$ & 967 & $3.42(.62)$ & 7.11 & $<.01$ & Supported \\
\hline $\mathrm{H} 4 \mathrm{c}$ & Conscientiousness & Personalization & 573 & $3.33(.61)$ & 1470 & $3.40(.64)$ & 4.45 & $<.05$ & Supported \\
\hline $\mathrm{H} 4 \mathrm{~d}$ & Conscientiousness & Social & 1705 & $3.37(.64)$ & 338 & $3.44(.61)$ & 2.71 & ns & Not supported \\
\hline $\mathrm{H} 4 \mathrm{e}$ & Conscientiousness & Finance & 875 & $3.42(.59)$ & 1168 & $3.36(.63)$ & 3.88 & $<.05$ & Not supported \\
\hline
\end{tabular}

Finally, H5 is tested by comparing the means of adopters' openness to experience with those of non-adopters among all types of mobile apps. No statistically significant difference can be found in any app category so that results are not reported in Table 3. Consequently, H5 is support.

\subsection{Accuracy of Predicting Personality Traits}

Before modeling the Big Five personality traits with mobile app data, the data set is cleaned according to the approach described in Section 4.2. This results to 1531 useable data points with one representing a participant. $70 \%$ or 1072 data points were randomly assigned into a training data set and the remaining $30 \%$ or 459 data points were assigned into a test set.

As shown in the previous hypotheses testing section, personality traits have positive or negative impact on the adoption of different types of mobile apps. Because more than half of the participants belong to the 'Medium' group in each of the Big Five traits, a model that focuses on the overall accuracy would predict most of the participants to be in the dominant class. However, people who belong to each 'High' and 'Low' group are more useful in decisionmaking applications because they behave differently from the majority (Wright \& Chin, 2014). Take participants of this study for example, the proportion of adopters of 'Personalization' apps among people who are high in neuroticism is $35 \%$ higher than that who are medium or low in neuroticism. Consequently, instead of treating 'High', 'Medium', and 'Low' groups equally, the predictive models focused on accurately classifying people in the 'High' 
and 'Low' groups of each Big Five trait. The prediction results are shown in Table 4.

There are in total ten prediction models with one predicting each target group. Precision is defined as the fraction of the retrieved instances that are relevant. It is a measure of the accuracy provided that a specific class has been predicted. On the other hand, recall is defined as the fraction of relevant instances that are retrieved and it is a measure of the ability of a model to select instances of a certain class from the whole data set.

The baseline for performance comparison is a random model, which is defined as randomly allocating each user in the test set into one of the three groups ('High', 'Medium', or 'Low') of each personality trait. The approach is similar to that of previous studies (Wright \& Chin, 2014). Take the first model Extraversion-High for example, $27.10 \%$ of instances that are predicted as high in extraversion by a random model are actually high, while the remaining $72.90 \%$ of instances are either low or medium in extraversion. On the other hand, the final predictive model generated by our algorithms is able to increase the prediction accuracy by $44.54 \%$ from $27.10 \%$ to $39.17 \%$. Overall, the prediction precision of random models is $25.81 \%$ on average while that of our predictive models are $42.72 \%$, which is $65.50 \%$ better. Given the large number of smartphone users, the recall rate covers a significant part of the population (26.94\%) and is comparable to similar studies (Wright \& Chin, 2014).

Table 4. Comparing Performance of Prediction Models $\left(\mathrm{N}_{\text {train }}=1072, \mathrm{~N}_{\text {test }}=459\right)$

\begin{tabular}{|c|c|c|c|c|c|c|}
\hline Prediction Group & $\begin{array}{r}\text { Precision of } \\
\text { Random }\end{array}$ & $\begin{array}{r}\text { Precision of Our } \\
\text { Model }\end{array}$ & Improvement & $\begin{array}{l}\text { Recall of } \\
\text { Random }\end{array}$ & $\begin{array}{r}\text { Recall of Our } \\
\text { Model }\end{array}$ & Improvement \\
\hline Extraversion-High & $27.10 \%$ & $39.17 \%$ & $44.54 \%$ & $32.56 \%$ & $36.43 \%$ & $11.89 \%$ \\
\hline Extraversion-Low & $23.57 \%$ & $51.61 \%$ & $118.96 \%$ & $31.36 \%$ & $13.56 \%$ & $-56.76 \%$ \\
\hline Neuroticism-High & $22.30 \%$ & $41.94 \%$ & $88.07 \%$ & $28.70 \%$ & $22.61 \%$ & $-21.22 \%$ \\
\hline Neuroticism-Low & $22.00 \%$ & $38.61 \%$ & $75.50 \%$ & $27.73 \%$ & $30.71 \%$ & $10.75 \%$ \\
\hline Agreeableness-High & $22.30 \%$ & $48.48 \%$ & $117.40 \%$ & $31.73 \%$ & $22.70 \%$ & $-28.46 \%$ \\
\hline Agreeableness-Low & $25.33 \%$ & $39.76 \%$ & $56.97 \%$ & $29.69 \%$ & $25.78 \%$ & $-13.17 \%$ \\
\hline Conscientiousness-High & $30.77 \%$ & $44.76 \%$ & $45.47 \%$ & $34.78 \%$ & $34.06 \%$ & $-2.07 \%$ \\
\hline Conscientiousness-Low & $28.99 \%$ & $36.36 \%$ & $25.42 \%$ & $28.57 \%$ & $48.57 \%$ & $70.00 \%$ \\
\hline Openness-High & $29.14 \%$ & $44.83 \%$ & $53.84 \%$ & $32.59 \%$ & $19.26 \%$ & $-40.90 \%$ \\
\hline Openness-Low & $26.62 \%$ & $41.67 \%$ & $56.54 \%$ & $32.28 \%$ & $15.75 \%$ & $-51.21 \%$ \\
\hline Average & $25.81 \%$ & $42.72 \%$ & $65.50 \%$ & $30.99 \%$ & $26.94 \%$ & $-13.08 \%$ \\
\hline
\end{tabular}

In addition, the top-three most powerful indicators in each of the ten Random Forest models are presented in Table 5. As shown in the table, number of apps and games installed in some specific categories, as well as app installation intervals are most frequently used by the Random Forest models in classification.

Table 5. Powerful Predictors Used in the Predictive Models

\begin{tabular}{lrrr}
\hline Prediction Group & First Most Important & Second Most Important & Third Most Important \\
\hline Extraversion-High & \# Apps in Board \& Word Game & \# Apps in Family \& Puzzle Game & \# Apps in Family \& Word Game \\
Extraversion-Low & \# Apps in Board \& Word Game & \# Apps in Family \& Puzzle Game & \# Apps in Education \\
Neuroticism-High & First Quartile Install Interval & \# App Install Days & Entropy of App Categories \\
Neuroticism-Low & \# Apps in Shopping & Maximum Monthly Install & \# Apps in Puzzle Game \\
Agreeableness-High & Median Install Interval & \# Apps in Trivia Game \& News & \# Apps in Casual Game \\
Agreeableness-Low & S.D. Install Interval & \# Apps in Life Style \& News & \# Apps in Life Style \& Casino Game \\
Conscientiousness-High & \# Apps in Video & Third Quartile Install Interval & \# Apps in Social \& Trivia Game \\
Conscientiousness-Low & \# Apps in Lifestyle \& Photography & \# Apps in Action Game \& Music & Age of the Phone
\end{tabular}


To illustrate how the machine learning approach can be used in practice, a mobile app prototype was further developed. It leverages the machine-learning models based on the user's mobile app data and predicts the corresponding user's personality traits. The predicted profiles of two users in our data set are shown in Figure 4. In addition to the Big Five personality traits, the predicted demographics like gender, age, and salary were also presented in the app to make it more relevant in practice. However, details about these additional predictive models as well as their performance are not discussed in this work.

The predictive confidence of each user characteristic is shown in the right-most column. As the Random Forest algorithm uses majority voting for classification problems, the value thus indicates how much percentage of decision trees votes the corresponding characteristic to be the value that is presented in the app. The confidence value lies between 0 and 1; the higher the value, the more confident the model is of the predicted characteristic. Due to the fact that there are three groups for each personality trait, a value that is much higher than 0.33 gives the model more confidence in its prediction. In the demo app, if a predictive model fails to allocate a case into the high or low group with a confidence level that is $20 \%$ higher than the baseline $(0.33)$, it will then show the corresponding characteristic to be unknown.
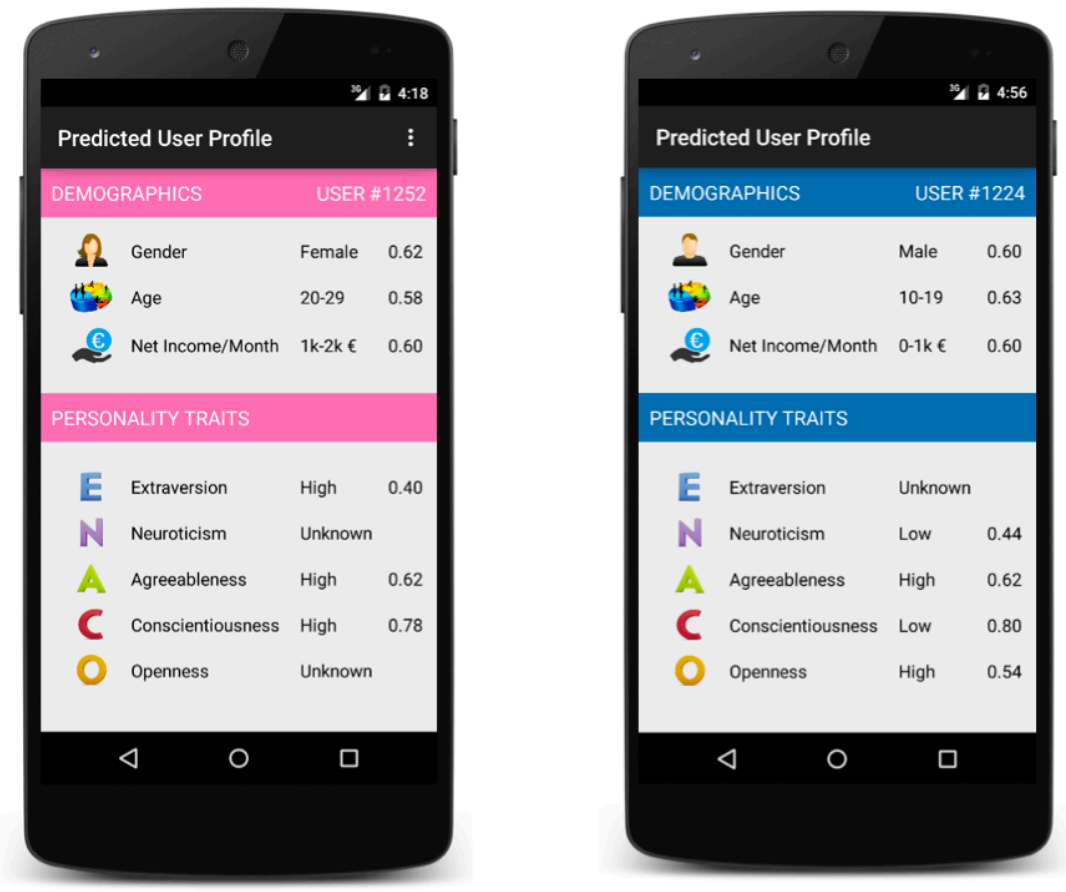

Fig. 4. A Demo App That Presents Each User's Predicted Profile

The user on the left side of Figure 4 is predicted to be a female in her twenties with a net monthly income between one and two thousand Euros. The model can be confident that she is highly conscientious and agreeable, however, although predicted to be an extravert, it is comparatively less confident because the corresponding confidence value is slightly above the threshold. Similarly, the right side of Figure 4 presents an example of a male smartphone user under twenty with low income. This user is very likely to be low in conscientiousness and high in agreeableness and openness, while whether he is an extravert remains unknown.

\section{Discussion, Limitation, and Future Work}

\subsection{Findings and Contributions}

Previous research revealed that the Big Five personality traits could have impact on individuals' adoption behavior of mobile apps. However, the mobile apps under study in previous literature were limited to a small 
number of mainstream apps like 'Facebook' and 'Twitter', which might prevent researchers from generalizing the findings to other apps of the same type. To demonstrate a more complete, integrated, and coherent view, a new framework is presented in this study to understand such impact on an app category level. Consequently, hypotheses were developed from previous literature and were tested with 2043 Android smartphone users. Instead of using selfreported questionnaire data, each participant's mobile app data was used to test the hypotheses. The advantages of this novel approach are two-fold. First, it goes beyond surveying a user's intention for app usage and leverage actual behavioral data to examine the impact of different personality traits on mobile app adoption. The unique data set provides a new perspective to understand adoption. Second, due to the fact that the data set logs all the mobile apps each participant has installed, this approach is not limited to analyze only a small number of specific apps. Instead, it is possible to analyze the impact of different personality traits on different app categories, as well as on any individual app. The findings contribute to advance the body of knowledge in adoption research and our novel data collection approach provides other researchers with a new tool to better understand adoption in the future.

This large-scale field study reveals that personality traits have a significant impact on people's adoption behavior of mobile apps and such impact differs from app categories to categories. For example, more conscientious people are found to be less likely to adopt leisure mobile apps such as music, photography, and personalization apps to avoid distraction from their productive activities. Nevertheless, neurotic individuals are likely to adopt such apps due to their fussy and picky nature as well as their interest in creative activities. In addition, introverts prefer to install mobile games, whereas less agreeable people tend to adopt personalization apps so as to customize their smartphones to be a better self-representation.

On the other hand, existing studies that are relevant to mobile app adoption typically take social apps under study due to their recent popularity. They showed that the Big Five personality traits are strongly correlated with the adoption of social apps. However, none of the previous findings (H1a, H2a, H3a, H4d) could be supported by this work. One explanation could be that social apps such as 'Facebook' and 'Whatsapp' are now becoming mainstream apps with most people ( $83 \%$ in our samples) have installed them, which narrows the differences on personality between adopters and non-adopters. As indicated by other studies (Ellison, Steinfield, \& Lampe, 2007; Ross et al., 2009), the impact of personality on adoption becomes weaker or even non-significant with the growing popularity of technologies and apps. Although not significant on app category level, we suspect that personality traits will have direct impact on sub-categories of social apps. For instance, adopters of apps that focus on photo sharing such as 'Snapchat' and 'Instagram' might be on average lower in neuroticism because sharing and communicating with photos could trigger more privacy concerns compared with text-based communication, which prohibits neurotic people from adopting.

Similarly, openness to experience has no impact on the adoption of any of the seven categories of mobile apps, as hypothesized in H5. Nevertheless, it does not mean that openness has no impact on mobile app adoption. According to early findings that open and innovative people are more likely to become early adopters of new technologies and services, it is suspected that openness will have a significant and positive impact on users' adoption of new apps that are not yet widely known. Due to the fact that the seven chosen app categories are popular among smartphone users, such an impact is weakened on the category level because it is difficult to distinguish early adopters from other users in the data set.

Although personality traits have impact on adoption, using the findings in reality to improve marketing effectiveness is still limited. In contrast to user demographics like age and gender, which can be guessed from look and feel or be sampled with simple questions, an individual's personality traits remain unknown until being measured by lengthy survey. Due to the gamification nature of our app, this work achieved a high survey completion rate $(96 \%)$. However, completion rate of similar studies is typically only around $30 \%$ (Nulty, 2008) because it is tedious and time-consuming to answering all the questions of measuring personality (Gosling et al., 2003). This might be one reason why compare to age and gender, the impact of personality on adoption is neglected in previous research (McElroy et al., 2007). To overcome the deficiency, a feasible, scalable and automatic machine-learning approach was developed to predict an individual's personality traits based on a snapshot of her app installation and update events. By leveraging this approach, personality becomes predictable for everyone who uses a smartphone without the pains of answering any kind of survey. The predictive models perform around $65 \%$ better than a random guess in classifying users based on their Big Five personality traits. Compared to the performance of similar studies (Chittaranjan et al., 2013; Montjoye et al., 2013), our proposed approach is able to achieve a similar or higher level of precision. Instead of being available only to phone manufacturers or telecommunication companies, data used in 
the approach is openly accessible. Therefore, everyone can leverage the approach and integrate the predictive models as part of her frontend mobile apps and/or backend customer relationship management or decision support systems. In addition, the approach complies with privacy laws and regulations in Europe.

\subsection{Managerial Implications}

This work has implications for managers and practitioners as well. First, it provides an overview of how different personality traits influence the adoption of different types of mobile apps. Based on the type of a new mobile app, managers will know who are more likely to become adopters of the app. For instance, less conscientious and more neurotic people are more likely to install a new personalization app while introverts are more likely to adopt a new mobile game. With the help of the machine-learning models, every app publisher is able to predict a smartphone user's personality traits with easily accessible data in real-time, as shown in the demo app in Figure 4. Consequently, instead of expensive mass marketing, app publishers can conduct personalized marketing (Dorotic, Bijmolt, \& Verhoef, 2012) by selecting targets based on their predicted personality traits thereby improving the effectiveness of their marketing campaigns.

In addition to use cases in mobile app adoption, managers can use the predictive models in other business context. Existing marketing literature shows that personality traits influence people's decision on product choice, purchasing behavior, store selection, brand loyalty, reaction to marketing campaigns, etc. (Kassarjian, 1971; Matzler, Bidmon, \& Grabner-Kräuter, 2006; Odekerken-Schröder, De Wulf, \& Schumacher, 2003). By combining such findings with our predictive models, firms are able to conduct better market segmentation and targeting, to improve customer relationship management, to enhance customer brand loyalty, as well as to cross-sell other products and services to potential adopters in their mobile apps.

Similarly, researchers revealed that different personalities influence the effectiveness of different mobile persuasive technologies. For instance, badges works better on introverts while progress bar is significantly preferred by people with high levels of agreeableness (Codish \& Ravid, 2014); Conscientious people are less likely to be motivated by socially-based technologies like leaderboard, whereas individuals with high openness are more likely to favor goal setting and leaderboard, as well as new persuasive technologies that they have not yet experienced (Brinkman \& Fine, 2005; Halko \& Kientz, 2010). Based on the predicted personality traits of each individual user, a mobile app could adapt its user interface and gamification features to the user's personality traits thereby further improving adoption. In addition to smartphones, the proposed approach can also be applied to other smart products (e.g. smart watches, glasses, TV boxes) to understand users' corresponding adoption behavior.

Although powerful, both retrieving mobile app data and conducting personalized marketing might trigger users' concern about privacy (Chen \& Hsieh, 2012; Lam, Frankowski, \& Riedl, 2006). Therefore, firms that leverage the approach should state explicitly to the corresponding app users regarding information like when and what data will be collected and for what purpose. Each well-designed app should be transparent on data collection. App publishers should also give users the right to opt-in for providing the mobile app data and for receiving personalized in-app recommendations and promotions, according to the suggestion from Pentland (2014). Nevertheless, compared to existing approaches that trace the installation of specific apps and phone call logs, our prediction model should lessen privacy concerns because only aggregated information like the total number of apps installed in each category and the frequency of installation is used by our approach.

\subsection{Limitations and Future Work}

There are several limitations of this paper, which provides opportunities for future research. First, although the sample size of this work is large compared to previous research, it is not representative in terms of age, gender and income. More than $75 \%$ of the samples are female and more than $70 \%$ of them are younger than 30 years old. This is understandable as the app was distributed on 'Facebook' and previous research shows that women are more likely to heavily use 'Facebook' and the like (Raacke \& Bonds-Raacke, 2008; Thompson \& Lougheed, 2012). Future research is thus called to confirm our findings with larger and more representative samples. In addition, personality traits are also dependent on culture and region. This first study only focuses on one European country. However, findings need to be tested in other countries for triangulation.

Second, the installation of apps was used to determine whether a user is an adopter of a specific app category or 
not. However, it is possible that some users have installed some apps but seldom use them. Taking a user's daily app usage into account could make it more accurate in deciding whether the user adopts a mobile app on a daily base or not. Google also provides APIs for developers to retrieve app activity logs on Android devices. Future research could leverage such information to gain more insights. On the other hand, new predictors generated from the additional API could also be used in the predictive models to further improve the performance of prediction. However, more granular data might also trigger higher privacy concerns. The trade-off between model precision and privacy concerns is also worth studying to find out the optimal balance.

Along with the discussion about social apps and H5, personality traits that have impact on app adoption in early stages might not be influential when the app becomes popular. Consequently, how the impact of personality traits on app adoption changes over time is also interesting and worth being studied in depth in the future.

Furthermore, in generating the machine-learning models, we found that many sub-categories of mobile games are strong indicators in predicting the Big Five personality traits, as shown in Table 5. Research on the impact of personality on game adoption exists for long time, however, to the best of our knowledge, how different personality traits impact the adoption of different types of mobile games is still not well studied systematically. Due to the large number and genre of mobile games, future research is called to better understand the adoption.

\section{Conclusion}

Research that focuses on understanding the impact of personality traits on mobile app adoption is scarce. Recent studies have started to address this gap, however, the small number of samples and limited range of apps make it difficult to generalize findings. As one of the first large-scale field studies, this work explores the influence of personality traits on mobile app adoption based on a snapshot of all the apps installed by 2043 Android users. It extends the body of knowledge on IS adoption research by identifying the impact of personality traits on individuals' adoption behavior of different types of mobile apps.

Personality traits are typically measured by a lengthy survey, which comes with difficulties regarding cost and scalability. Therefore, a machine-learning model is developed to automatically predict each smartphone user's Big Five personality traits based on her mobile app data. The model shows a $65 \%$ higher precision than a random guess. Compared with other data-driven approaches, our approach can be integrated into any mobile app because it uses easily accessible data through standard APIs. Furthermore, a mobile prototype is developed to demonstrate how practitioners could use the predictive model. For example, enabling other services such as improving user experience and conducting personalized marketing.

Aside from the two above contributions, the data collection approach used in this work is also novel. With this approach, researchers are able to go beyond intention and use actual behavioral data to understand each individual's mobile app adoption pattern. Additionally, as information becomes available about all the apps installed by each user, researchers are not limited to analyze only a small number of specific apps. One drawback of the approach is that it does not reflect how frequently a user accesses each app. Nevertheless, this can be overcome by calling other Google APIs in an Android app.

Finally, this work outlines future research opportunities, such as studying a more balanced gender sample, the stability of our approach over time, the impact of app novelty for different adoption stages and the impact of regional and cultural differences. 


\section{References}

Agarwal, R., \& Prasad, J. (1998). A Conceptual and Operational Definition of Personal Innovativeness in the Domain of Information Technology. Information Systems Research, 9(2), 204-215.

Ajzen, I. (1985). From Intentions to Actions: A Theory of Planned Behavior. In SSSP Springer Series in Social Psychology (pp. 11-39). Springer Berlin Heidelberg.

Ajzen, I., \& Fishbein, M. (1980). Understanding Attitudes and Predicting Social Behavior. Prentice-Hall.

Amiel, T., \& Sargent, S. L. (2004). Individual Differences in Internet Usage Motives. Computers in Human Behavior, 20(6), 711-726.

Arts, J. W. C., Frambach, R. T., \& Bijmolt, T. H. A. (2011). Generalizations on Consumer Innovation Adoption: A Meta-Analysis on Drivers of Intention and Behavior. International Journal of Research in Marketing, 28(2), 134-144.

Bachrach, Y., Kosinski, M., Graepel, T., Kohli, P., \& Stillwell, D. (2012). Personality and Patterns of Facebook Usage. In Proceedings of the 3rd Annual ACM Web Science Conference (pp. 24-32). New York, NY, USA.

Barrick, M. R., \& Mount, M. K. (1991). The Big Five Personality Dimensions and Job Performance: A Meta-Analysis. Personnel Psychology, 44(1), 1-26.

Barrick, M. R., \& Mount, M. K. (2000). Select on Conscientiousness and Emotional Stability. In E. A. Locke (Ed.), Handbook of Principles of Organizational Behavior (pp. 15-28). Blackwell Publishing Inc.

Benson, M. J., \& John, C. P. (2007). To Be, or Not to Be, Linear: An expanded representation of personality and its relationship to leadership performance. International Journal of Selection and Assessment, 15(2), 232-249.

Bergkvist, L., \& Rossiter, J. R. (2007). The Predictive Validity of Multiple-Item Versus Single-Item Measures of the Same Constructs. Journal of Marketing Research, 44(2), 175-184.

Bettman, J. R. (1979). Issues in Research on Consumer Choice. Advances in Consumer Research, 6(1), 214-217.

Bosnjak, M., Tuten, T. L., \& Wittmann, W. W. (2005). Unit (non)Response in Web-Based Access Panel Surveys: An Extended PlannedBehavior Approach. Psychology and Marketing, 22(6), 489-505.

Brancheau, J. C., \& Wetherbe, J. C. (1990). The Adoption of Spreadsheet Software: Testing Innovation Diffusion Theory in the Context of EndUser Computing. Information Systems Research, 1(2), 115-143.

Brinkman, W., \& Fine, N. (2005). Towards Customized Emotional Design: An Explorative Study of User Personality and User Interface Skin Preferences. In Proceedings of The 2005 Annual Conference on European Association of Cognitive Ergonomics (pp. 107-114). Athens, Greece.

Butt, S., \& Phillips, J. G. (2008). Personality and Self Reported Mobile Phone Use. Computers in Human Behavior, 24(2008), 346-360.

Chen, P. T., \& Hsieh, H. P. (2012). Personalized Mobile Advertising: Its Key Attributes, Trends, and Social Impact. Technological Forecasting and Social Change, 79(3), 543-557.

Childers, T. L., \& Ferrell, O. C. (1979). Response Rates and Perceived Questionnaire Length in Mail Surveys. Journal of Marketing Research, $16(3), 429-432$

Chin, D. N., \& Wright, W. R. (2014). Social Media Sources for Personality Profiling. In Proceedings of The 2nd Workshop Emotions and Personality in Personalized Services.

Chittaranjan, G., Blom, J., \& Gatica-Perez, D. (2013). Mining Large-Scale Smartphone Data for Personality Studies. Personal and Ubiquitous Computing, 17(3), 433-450.

Chorley, M. J., Whitaker, R. M., \& Allen, S. M. (2015). Personality and Location-Based Social Networks. Computers in Human Behavior, 46(1), 45-56.

Choudrie, J., Pheeraphuttharangkoon, S., Zamani, E., \& Giaglis, G. (2014). Investigating the Adoption and Use of Smartphones in the UK: A Silver-Surfers Perspective. In Proceedings of the 22nd European Conference on Information Systems (pp. 0-19). Tel Aviv, Israel.

Codish, D., \& Ravid, G. (2014). Personality Based Gamificaiton: How Differente Personalities Perceive Gamification. In Proceedings of the 22nd European Conference on Information Systems. Tel Aviv, Israel.

Conner, M., \& Armitage, C. J. (1998). Extending the Theory of Planned Behavior: A Review and Avenues for Further Research. Journal of Applied Social Psychology, 28(15), 1429-1464.

Constantiou, D., Damsgaard, J., \& Knutsen, L. A. (2006). Exploring Perceptions and Use of Mobile Services: User Differences in an Advancing Market. International Journal of Mobile Communications, 4(3), 231-247.

Correa, T., Hinsley, A. W., \& de Zúñiga, H. G. (2010). Who Interacts on the Web?: The Intersection of Users' Personality and Social Media Use. Computers in Human Behavior, 26(2), 247-253.

Costa, P. T., \& McCrae, R. R. (1985). The NEO Personality Inventory: Manual Form S and Form R. Psychological Assessment Resources.

Costa, P. T., \& McCrae, R. R. (1992). Revised NEO Personality Inventory (NEO-PI-R) and NEO Five-Factor Inventory (NEO-FFI) Professional Manual. Odessa, FL: Psychological Assessment Resources. 
Cramer, E. M., \& Bock, R. D. (1966). Multivariate analysis. Review of Educational Research, (36), 604-617.

Cucina, J. M., \& Vasilopoulos, N. L. (2005). Nonlinear Personality-Performance Relationships and the Spurious Moderating Effects of Traitedness. PubMed, 73(1), 227-259.

Davis, F. D. (1989). Perceived Usefulness, Perceived Ease of Use, and User Acceptance of Information Technology. MIS Quarterly, 13(3), 319340 .

Devaraj, U. S., Easley, R. F., \& Michael Crant, J. (2008). How Does Personality Matter? Relating the Five-Factor Model to Technology Acceptance and Use. Information Systems Research, 19(1), 93-105.

Digman, J. M. (1990). Personality Structure: Emergence of the Five-Factor Model. Annual Review of Psychology, 41(1), 417-440.

Dorotic, M., Bijmolt, T. H. A., \& Verhoef, P. C. (2012). Loyalty Programmes: Current Knowledge and Research Directions. International Journal of Management Reviews, 14(3), 217-237.

Dwivedi, Y., Williams, M., Ramdani, B., Niranjan, S., \& Weerakkody, V. (2011). Understanding Factors for Successful Adoption of Web 2.0 Applications. In Proceedings of the 19th European Conference on Information Systems.

Ellison, N. B., Steinfield, C., \& Lampe, C. (2007). The Benefits of Facebook “Friends:” Social Capital and College Students' Use of Online Social Network Sites. Journal of Computer-Mediated Communication, 12(4), 1143-1168.

Eysenck, H. J. (1947). Dimensions of Personality. New York Praeger.

Gelade, G. A. (1997). Creativity in Conflict: The Personality of the Commercial Creative. Journal of Genetic Psychology, $158,67-68$.

Godin, G., \& Kok, G. (1996). The Theory of Planned Behavior: A Review of Its Applications to Health-related Behaviors. American Journal of Health Promotion, 11(2), 87-98.

Goldberg, L. R. (1992). The Development of Markers for the Big-Five Factor Structure. Psychological Assessment, 4(1), 26-42.

Gosling, S. D., Rentfrow, P. J., \& Swann, W. B. (2003). A Very Brief Measure of the Big-Five Personality Domains. Journal of Research in Personality, 37(6), 504-528.

Guo, G., Fu, Y., Dyer, C. R., \& Huang, T. S. (2008). A Probabilistic Fusion Approach to Human Age Prediction. In 2008 IEEE Computer Society Conference on Computer Vision and Pattern Recognition Workshops. Anchorage, AK, USA.

Guyon, I., \& Elisseeff, A. (2003). An Introduction to Variable and Feature Selection. Journal of Machine Learning Research, 3, $1157-1182$.

Halko, S., \& Kientz, J. A. (2010). Personality and Persuasive Technology: An Exploratory Study on Health-Promoting Mobile Applications. In Proceedings of The 5th International Conference on Persuasive Technology (pp. 150-161). Copenhagen, Denmark.

Han, H., Otto, C., Liu, X., \& Jain, A. (2014). Demographic Estimation from Face Images: Human vs. Machine Performance. IEEE Transactions on Pattern Analysis and Machine Intelligence, PP(99), 1-14.

Hastie, T., Tibshirani, R., \& Friedman, J. (2009). The Elements of Statistical Learning: Data Mining, Inference, and Prediction (Second Edi). Springer New York.

Ho, T. K. (1995). Random Decision Forests. In Proceedings of the Third International Conference on Document Analysis and Recognition (pp. 278-282). Montreal, Canada.

Hughes, D. J., Rowe, M., Batey, M., \& Lee, A. (2012). A Tale of Two Sites: Twitter vs. Facebook and the Personality Predictors of Social Media Usage. Computers in Human Behavior, 28(2), 561-569.

James, G., Witten, D., Hastie, T., \& Tibshirani, R. (2014). An Introduction to Statistical Learning: With Applications in R. (G. Casella, S. Fienberg, \& I. Olkin, Eds.). Springer.

John, O. P., \& Srivastava, S. (1999). The Big Five Trait Taxonomy: History, Measurement, and Theoretical Perspectives. Handbook of Personality: Theory and Research, 2(1), 102-138.

Judge, T. A., Heller, D., \& Mount, M. K. (2002). Five-Factor Model of Personality and Job Satisfaction: A Meta-Analysis. Journal of Applied Psychology, 87(3), 530-541.

Kassarjian, H. H. (1971). Personality and Consumer Behavior: A Review. Journal of Marketing Research, 8, 409-418.

King, L., Walker, M. L., \& Broyles, S. J. (1996). Creativity and the five-Factor Model. Journal of Research in Personality, $30,189-203$.

Kosinski, M., Stillwell, D., \& Graepel, T. (2013). Private Traits and Attributes Are Predictable from Digital Records of Human Behavior. Proceedings of the National Academy of Sciences of the United States of America, 110(15), 5802-5.

Kucukyilmaz, T., Cambazoglu, B., Aykanat, C., \& Can, F. (2006). Chat Mining for Gender Prediction. Advances in Information System Lecture Notes in Computer Science. Springer-Verlag Berlin Heidelberg.

Lam, S. K. T., Frankowski, D., \& Riedl, J. (2006). Do You Trust Your Recommendations? An Exploration Of Security and Privacy Issues in Recommender Systems. In International Conference on Emerging Trends in Information and Communication Security. Freiburg, Germany.

Landers, R. N., \& Lounsbury, J. W. (2006). An Investigation of Big Five and Narrow Personality Traits in Relation to Internet Usage. Computers in Human Behavior, 22(2), 283-293.

Leonard-Barton, D., \& Deschamps, I. (1988). Managerial Influence in the Implementation Of New Technology. Management Science, 34(10), 
$1252-1265$

Liu, C. ., Au, Y. ., \& Choi, H. . (2014). An Empirical Study of the Freemium Strategy for Mobile Apps: Evidence from the Google Play Market. Journal of Management Information Systems, 31(3), 326-354.

Maccallum, R. C., Zhang, S., Preacher, K. J., \& Rucker, D. D. (2002). On the Practice of Dichotomization of Quantitative Variables. Psychological Methods, 7(1), 19-40.

MacNicol, S. a M., Murray, S. M., \& Austin, E. J. (2003). Relationships between Personality, Attitudes and Dietary Behaviour in a Group of Scottish Adolescents. Personality and Individual Differences, 35(8), 1753-1764.

Matzler, K., Bidmon, S., \& Grabner-Kräuter, S. (2006). Individual Determinants of Brand Affect: The Role of the Personality Traits of Extraversion and Openness to Experience. Journal of Product \& Brand Management, 15(7), 427-434.

McCrae, R., \& Costa, P. T. (2004). A Contemplated Revision of the NEO Five-Factor Inventory. Personality and Individual Differences, 36 , 587-596.

Mccrae, R. R., \& Costa, P. T. (1987). Validation of the Five-Factor Model of Personality Across Instruments and Observers. Journal of Personality and SocialPsychology, 52(1), 81-90.

McElroy, J. C., Hendrickson, A. R., Townsend, A. M., \& DeMarie, S. M. (2007). Dispositional Factors in Internet Use - Personality Versus Cognitive Style. MIS Quarterly, 31(4), 809-820.

Meng, L., Liu, S., \& Striegel, A. D. (2014). Analyzing the Impact of Proximity, Location, and Personality on Smartphone Usage. Computational Social Networks, 1(6), 293-298.

Menzel, H. (1960). Innovation, Integration, and Marginality : A Survey of Physicians. American Sociological Review, 25(5), 704-713.

Meyers, L. S., Gamst, G., \& Guarino, A. (2013). Applied Multivariate Research: Design and Interpretation (Second Edi). SAGE Publications Inc.

Minamikawa, A., Fujita, H., Hakura, J., \& Kurematsu, M. (2012). Personality Estimation Application for Social Media. The Frontiers in Artificial Intelligence and Applications. IOS Press.

Montjoye, Y. De, Quoidbach, J., \& Robic, F. (2013). Predicting Personality Using Novel Mobile Phone-Based Metrics. In Social Computing, Behavioral-Cultural Modeling and Prediction (pp. 48-55). Springer Berlin Heidelberg.

Moore, G. C., \& Benbasat, I. (1991). Development of an Instrument to Measure the Perceptions of Adopting an Information Technology Innovation. Information Systems Research, 2(3), 192-222.

Nguyen, D., Smith, N., \& Rosé, C. (2011). Author Age Prediction from Text Using Linear Regression. In Proceedings of the 5th ACL-HLT Workshop on Language Technology for Cultural Heritage, Social Sciences, and Humanities (pp. 115-123). Stroudsburg, PA, USA.

Norman, W. T. (1963). Toward an Adequate Taxonomy of Personality Attributes: Replicated Factor Structure in Peer Nomination Personality Ratings. The Journal of Abnormal and Social Psychology, 66(6), 574-583.

Nulty, D. D. (2008). The Adequacy of Response Rates to Online and Paper Surveys: What Can Be Done? Assessment \& Evaluation in Higher Education, 33(3), 301-314.

Nunnally, J. C. (1967). Psychometric Theory. New York: McGraw-Hill.

Odekerken-Schröder, G., De Wulf, K., \& Schumacher, P. (2003). Strengthening Outcomes of Retailer-Consumer Relationships. The Dual Impact of Relationship Marketing Tactics and Consumer Personality. Journal of Business Research, 56(3), 177-190.

Pan, W., Aharony, N., \& Pentland, A. (2011). Composite Social Network for Predicting Mobile Apps Installation. In Proceedings of The TwentyFifth AAAI Conference on Artificial Intelligence (pp. 821-827). San Francisco, California.

Penney, L. M., David, E., \& Witt, L. A. (2011). A Review of Personality and Performance: Identifying boundaries, Contingencies, and Future Research Directions. Human Resource Management Review, 21(4), 297-310.

Pentland, A. (2014). Social Physics: How Good Ideas Spread: the Lessons from a New Science. Scribe Publications Pty Limited.

Pianesi, F., Mana, N., Cappelletti, A., Lepri, B., \& Zancanaro, M. (2008). Multimodal Recognition of Personality Traits in Social Interactions. In Proceedings of The 10th International Conference on Multimodal Interfaces (pp. 53-60). New York, USA: ACM Press.

Porter, S. R. (2004). Raising Response Rates: What Works? New Directions for Institutional Research, 1(121), 5-21. doi:10.1002/ir.97

Post, F. (1994). Creativity and Psychopathology: A Study of World-Famous Men. British Journal of Psychiatry, 168, 545-555.

Raacke, J., \& Bonds-Raacke, J. (2008). MySpace and Facebook: Applying the Uses and Gratifications Theory to Exploring Friend-Networking Sites. Cyberpsychology \& Behavior, 11(2), 169-174.

Rogers, E. (1995). Diffusion of Innovations. New York: Free Press.

Ross, C., Orr, E. S., Sisic, M., Arseneault, J. M., Simmering, M. G., \& Orr, R. R. (2009). Personality and Motivations Associated with Facebook Use. Computers in Human Behavior, 25(2), 578-586.

Ryan, T., \& Xenos, S. (2011). Who Uses Facebook? An Investigation into the Relationship between The Big Five, Shyness, Narcissism, Loneliness, and Facebook Usage. Computers in Human Behavior, 27(5), 1658-1664.

Scornavacca, E., \& Barnes, S. J. (2006). Barcode Enabled M-Commerce : Strategic Implications and Business Models. International Journal 
Mobile Communications, 4(2), 163-177.

Seneviratne, S., Seneviratne, A., Mohapatra, P., \& Mahanti, A. (2014). Predicting User Traits from a Snapshot of Apps Installed on a Smartphone. ACM Mobile Computing and Communications Review, 18(4), 1-8.

Shannon, C. E., \& Weaver, W. (1963). The Mathematical Theory of Communication. University of Illinois Press.

Sheeran, P. (2002). Intention-Behavior Relations: A Conceptual and Empirical Review. European Review of Social Psychology, 12 (1), 1-36.

Shen, J., Brdiczka, O., \& Liu, J. (2013). Understanding Email Writers: Personality Prediction from Email Messages. In The 21st International Conference on User Modeling, Adaptation and Personalization (pp. 318-330). Rome, Italy.

Shen, J., Brdiczka, O., \& Liu, J. (2015). A Study of Facebook Behavior : What Does It Tell about Your Neuroticism and Extraversion? Computers in Human Behavior, 46(1), 32-38.

Sproles, G. B., \& Kendall, E. L. (1986). A Methodology for Profiling Consumers' Decision-Making Styles. The Journal of Consumer Affairs, 20(2), 267-279.

Statista. (2014). Number of Apps Available in Leading App Stores as of July 2014. In Statista. Visited on March 09, 2015. Retrieved from http://www.statista.com/statistics/276623/number-of-apps-available-in-leading-app-stores/

Swickert, R. J., Hittner, J. B., Harris, J. L., \& Herring, J. A. (2002). Relationship Between Internet Use, Personality and Social Support. Computers in Human Behavior, 18(4), 437-451.

Tan, W. K., \& Yang, C. Y. (2014). Internet Applications Use and Personality. Telematics and Informatics, 31(1), $27-38$. doi:10.1016/j.tele.2013.02.006

Taylor, S., \& Todd, P. A. (1995). Understanding Information Technology Usage: A Test of Competing Models. Information Systems Research, $6(2), 144-176$.

Thompson, S. H., \& Lougheed, E. (2012). Frazzled by Facebook? An Exploratory Study of Gender Differences in Social Network Communication among Undergraduate Men and Women. College Student Journal, 46(1), 88-99.

Trestian, I., \& Nucci, A. (2009). Measuring Serendipity : Connecting People, Locations and Interests in a Mobile 3G Network. In Proceedings of The Internet Measurement Conference.

Tuten, T., \& Bosnjak, M. (2001). Understanding Differences in Web Usage: The Role of Need for Cognition and the Five Factor Model of Personality. Social Behavior and Personality, 29(4), 391-398.

Uffen, J., Kaemmerer, N., \& Breitner, M. H. (2013). Personality Traits and Cognitive Determinants - An Empirical Investigation of the Use of Smartphone Security Measures. Journal of Information Security, 2013(10), 203-212.

Venkatesh, V., Brown, S., \& Hoehle, H. (2012). Understanding Technology Adoption in the Hosehold Context: A Comparison of Seven Theoretical Models. In ECIS 2012 Proceedings.

Venkatesh, V., Morris, M. G., \& Davis, F. D. (2003). User Acceptance of Information Technology : Toward a Unified View. MIS Quarterly, 27(3), 425-478.

Venkatesh, V., \& Susan, A. B. (2001). A Longitudinal Investigation of Personal Computers in Homes- Adoption Determinants and Emerging Challenges. MIS Quarterly, 25(1), 71-102.

Venkatesh, V., Thong, J. Y., \& Xu, X. (2012). Consumer Acceptance and Use of Information Technology: Extending the Unified Theory of Acceptance and Use of Technology. MIS Quarterly, 36(1), 157-178.

Watson, D., \& Clark, L. A. (1997). Extraversion and Its Positive Emotional Core. In R. Hogan, J. Johnson, \& S. Briggs (Eds.), Handbook of personality psychology (pp. 767-793). San Diego, CA, USA: Academic Press.

Weimann, G., \& Hans-Bernd, B. (1994). Is There a Two-Step Flow of Agenda-Setting? Int.J.Publ.Opin.Res, 6, $323-341$.

Wejnert, B. (2002). Integrating Models of Diffusion of Innovations A Conceptual Framework. Annual Review of Sociology, $28(1), 297-326$.

Wright, W. R., \& Chin, D. N. (2014). Personality Profiling from Text : Introducing Part-of-Speech N -Grams. In The 22nd Conference on User Modeling, Adaptation and Personalization (pp. 243-253). Aalborg, Denmark.

Ying, J. J., Chang, Y., Huang, C., \& Tseng, V. S. (2007). Demographic Prediction Based on User's Mobile Behaviors. In Proceedings of the 16th International Conference on World Wide Web (pp. 151-160). New York, NY, USA.

Zhu, K., Dong, S., Xu, S. X., \& Hally, M. (2006). Innovation Diffusion in Global Contexts: Determinants of Post-Adoption Digital Transformation of European Companies. European Journal of Information Systems, 15(6), 601-616. 